\title{
Avaliando a usabilidade da interface da comunidade virtual do Muzar
}

\author{
Aline Posser ${ }^{1}$ \\ Ana Carolina Bertoletti De Marchi ${ }^{1}$
}

\begin{abstract}
Resumo: A CV-Muzar é uma comunidade de aprendizagem informal disponível aos visitantes do Museu Zoobotânico Augusto Ruschi, com o objetivo de propiciar a experimentação de recursos, a construção de problemas e comunicação de ideias por meio um espaço de encontros e convivências. Um dos aspectos fundamentais para o sucesso das comunidades está relacionado ao processo de interação e, como consequência, a facilidade de uso e aprendizagem da interface - a usabilidade. Este trabalho descreve a avaliação da usabilidade da interface da CV-Muzar por meio de inspeção com vistas a melhorar as interações assíncronas entre os participantes da comunidade.
\end{abstract}

Palavras-chave: Comunidade virtual. CV-Muzar. Usabilidade.

\begin{abstract}
The CV-Muzar is an informal learning community available to visitors of the Zoobotanical Augusto Ruschi Museum with the goal of providing resources for experimentation, problems construction and communications of ideas through a meeting and living together space. One of the keys to the success of the communities is related to the process of interaction and, consequently, the ease of use and learning of the interface - the usability. This paper describes the evaluation of interface usability of CV-Muzar through inspection with view to improve the asynchronous interactions among community participants.
\end{abstract}

Keywords: CV-Muzar. Usability. Virtual community.

\section{Introdução}

Uma comunidade virtual nos moldes da CV-Muzar é aquela voltada a promover um ambiente que favorece a construção de conhecimento, cujos membros estão relacionados com objetivos em comum de aprendizagem. Essas comunidades podem promover a aprendizagem seguindo uma estrutura formal ou informal. Quando mencionamos o modo formal, estamos considerando que a comunidade irá se formar com base numa estrutura física real, onde encontramos a figura do professor como facilitador e do aluno como sujeito ativo na construção de seu conhecimento. Por sua vez, para a formação de comunidades de aprendizagem informal, é necessário contar com os interesses pessoais de seus membros, de modo a definir uma rede de relacionamento auto-organizada, proporcionada pela comunicação interativa, levando a uma aprendizagem contínua e permanente.[1]

Para que uma comunidade virtual de aprendizagem informal tenha sucesso e seja efetivamente utilizada, é fundamental que esta leve em conta alguns fatores essenciais para que o usuário se cadastre e usufrua das suas funcionalidades. Entre esses fatores destacam-se: ser uma ferramenta fácil de aprender e manipular; que sua interface seja atrativa; que tenha um objetivo especificado, para que o usuário possa realizar eficientemente os seus objetivos como membro da comunidade.

\footnotetext{
${ }^{1}$ Curso de Ciência da Computação, UPF, Campus 1 - BR 285 - Passo Fundo (RS) - Brasil. \{83461, carolina@upf.br\}
}

http://dx.doi.org/10.5335/rbca.2012.2060 
Nesse sentido, a avaliação da usabilidade de interfaces é uma etapa que deve ser considerada dentro do ciclo de vida de um sistema e seu objetivo é identificar problemas que possam comprometer a interação do usuário com a interface. Este tipo de avaliação é particularmente importante para comunidades virtuais de aprendizagem, pois além dos produtos com baixa usabilidade serem geralmente responsáveis por frustração, ansiedade e baixa produtividade, podem levar o participante a conclusões equivocadas ou errôneas, impedindo que o usuário amplie seu conhecimento e causando desinteresse no aprendizado.

Como a verificação da usabilidade vem sendo vista como uma etapa fundamental no desenvolvimento de ferramentas virtuais, foram desenvolvidos vários métodos para avaliar a usabilidade de uma interface. Esses métodos são classificados como métodos de inspeção da usabilidade e testes empíricos com os usuários. Para realizar uma análise mais abrangente do produto, podem ser aplicadas mais de uma técnica a uma mesma interface.

Na avaliação da interface da CV-Muzar utilizou-se o método de inspeção da usabilidade, verificando os principais atributos referentes à usabilidade, onde foram examinados aspectos da interface por meio de heurísticas e em conformidade com a normativa ISO 9241-11.

Os resultados dessa avaliação serão apresentados neste artigo, juntamente com um breve histórico da CV-Muzar e os princípios de usabilidade.

\section{Um pouco sobre a CV-Muzar}

A CV-Muzar (Comunidade Virtual do Muzar) é um espaço de encontros e convivências que proporciona discussões intelectuais, troca de conhecimentos e compartilhamento de ideias, entre pessoas com objetivos semelhantes, que o fazem dirigidos apenas por seus interesses e necessidades pessoais.[2]

A presente ferramenta possibilita a conexão, aprendizagem e interação entre os visitantes do museu, proporcionando um espaço de aprendizagem informal. O objetivo é que o ambiente favoreça a aprendizagem ao longo da vida, de forma casual e espontânea, sem a existência de uma estrutura rígida e curricular, sendo o próprio usuário seu orientador, ampliando seu conhecimento de acordo com a área que mais o interessa.

Além de propiciar a pesquisa, o participante tem à sua disposição um conjunto de ferramentas de comunicação, troca de informações, upload e download de produções. As ferramentas de comunicação fornecem as facilidades que permitem a troca e o envio de informações para possibilitar o trabalho cooperativo entre os visitantes, possibilitando a interação por meio de mecanismos de discussão textual assíncrono no estilo de fóruns (fórum), de bate-papo síncrono textual (chat), e de lista de discussão por meio de correio eletrônico.

Ainda, na CV-Muzar o visitante é estimulado a contribuir por meio de produções pessoais, as quais são entendidas como um movimento de reconstrução que envolve a reflexão, questionamentos, busca por novos conhecimentos, argumentação e explicitação de diferentes opiniões. Essas produções são incorporadas ao acervo da comunidade, tornando-se mais uma fonte de consulta. Na verdade, as produções são objetos de aprendizagem (OAs) construídos pelos visitantes. As produções podem ser documentos, multimídias, e tudo que for relevante para a aplicação e que o visitante considere importante para os demais participantes.

Uma característica importante do ambiente é que qualquer usuário pode efetuar anotações na produção de outro usuário. Essa ferramenta tem como objetivo fazer com que as contribuições dos visitantes sejam consideradas para o crescimento do trabalho intelectual. As anotações também podem ser utilizadas para a construção de uma produção coletiva, na qual todos contribuem. Com a ferramenta de produção, todo o participante da comunidade é considerado um autor e sua contribuição auxilia na construção do acervo de OAs do ambiente. Além disso, da mesma forma que o visitante pode contribuir para o aperfeiçoamento ou construção de uma produção do usuário, também pode realizar anotações a respeito dos recursos de aprendizagem do museu, influenciando a mensagem expositiva e contribuindo na construção da estratégia comunicativa do espaço.

As Figuras 1 e 2 ilustram, respectivamente, a tela inicial da CV-Muzar e a tela após o usuário efetuar o login. Na primeira, o usuário tem a opção de fazer o login ou, caso ainda não esteja cadastrado, realizar o cadastro para participar da comunidade, além de saber quem são os desenvolvedores dessa ferramenta e as principais notícias relacionadas ao museu e à comunidade virtual.

Revista Brasileira de Computação Aplicada (ISSN 2176-6649), Passo Fundo, v. 4, n. 1, p. 38-47, mar. 201239 
Já a Figura 2 apresenta as principais funções da comunidade, dentre as quais destacam-se: listar fóruns de discussão; mapas de tópicos; produções dos visitantes; recursos disponíveis; acesso aos bate-papos; lista de participantes; meus dados; listar subcomunidades existentes; criar uma nova subcomunidade e convidar um novo participante para integrar-se à rede.

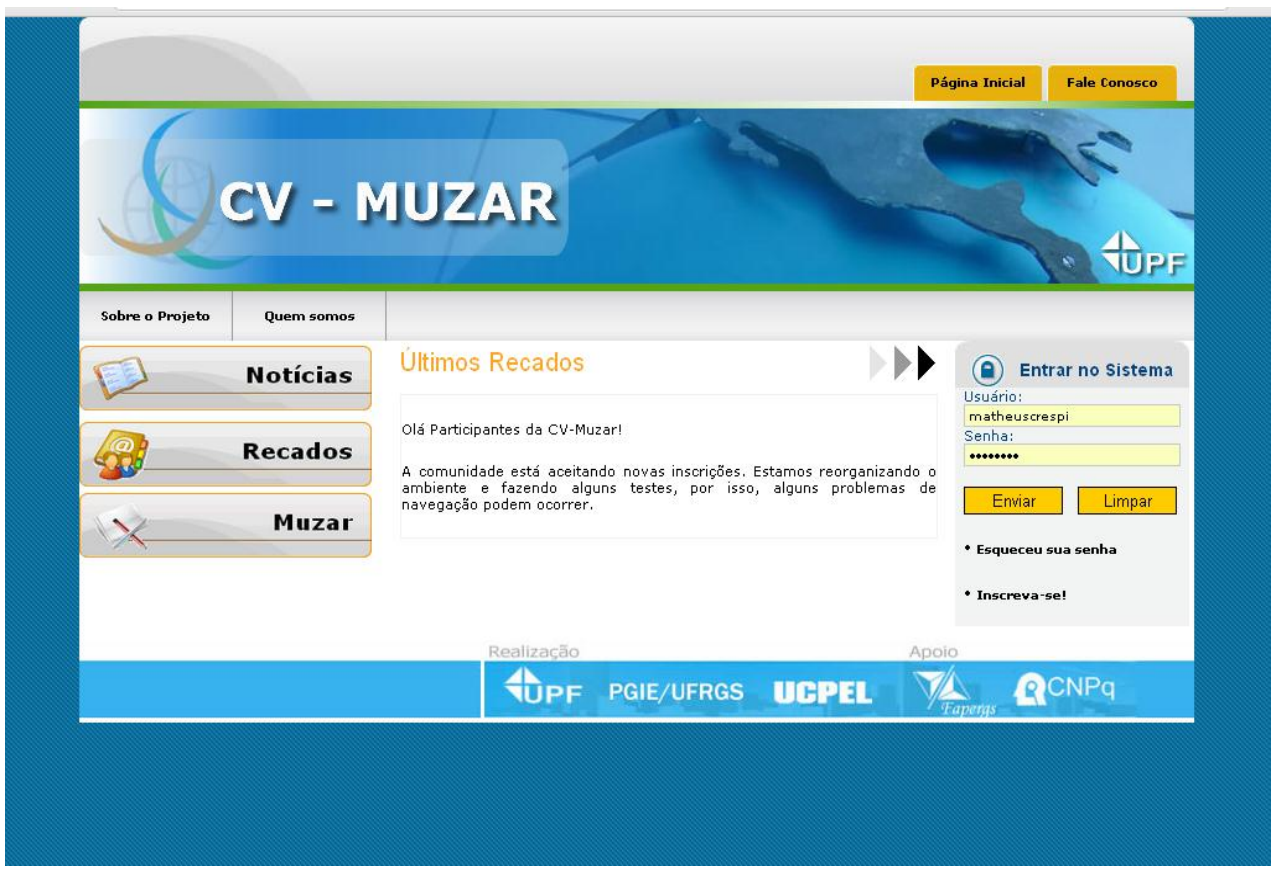

Figura 1: Tela principal da CV-Muzar

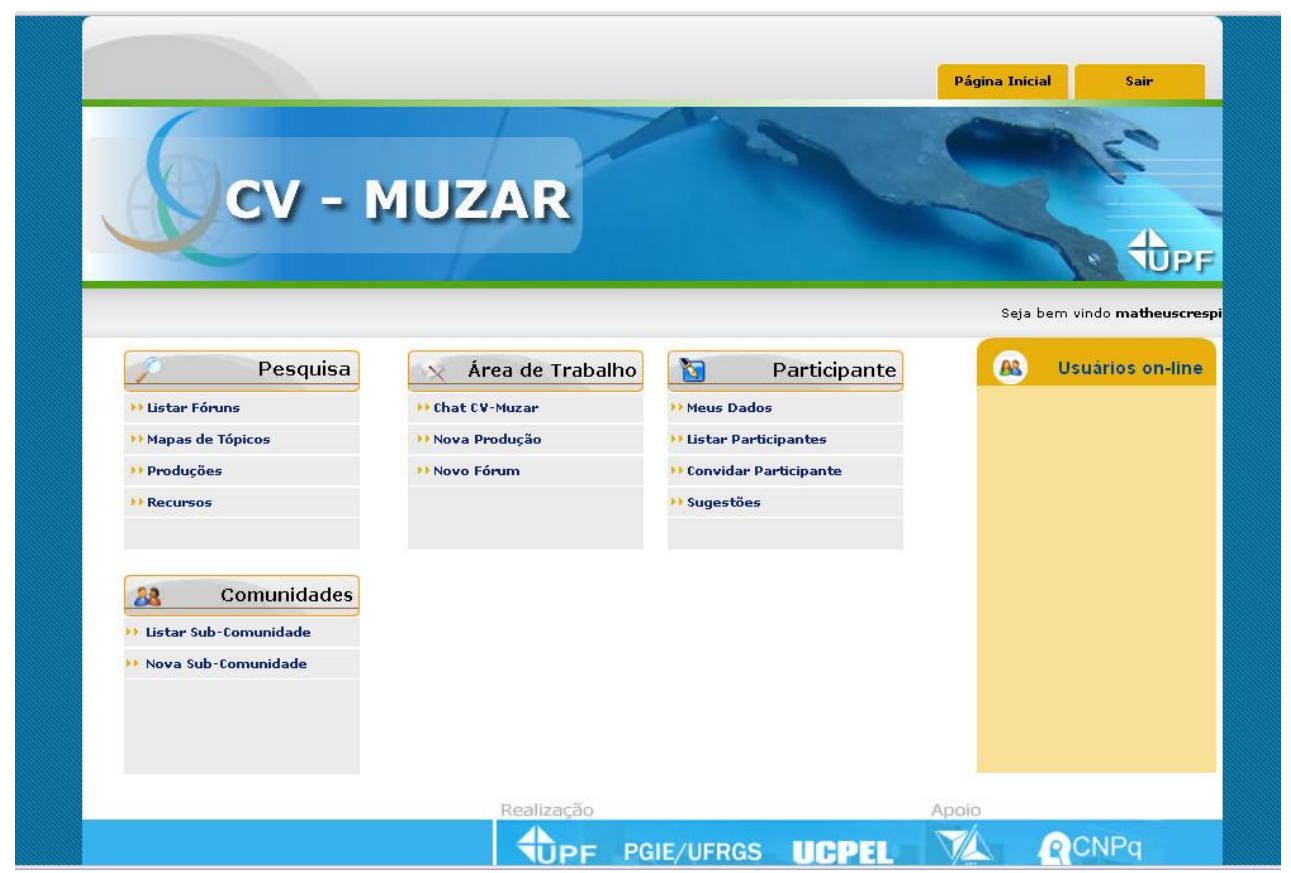

Figura 2: Tela do usuário logado na CV-Muzar 


\title{
3 Usabilidade de interfaces na web
}

Por usabilidade entende-se a "medida na qual um produto pode ser usado por usuários específicos para alcançar objetivos específicos com eficácia, eficiência e satisfação em um contexto específico de uso" [3].

E ainda,

\begin{abstract}
é um atributo de qualidade relacionado à facilidade do uso de algo. Mais especificamente, refere-se à rapidez com que os usuários podem aprender a usar alguma coisa, a eficiência deles ao usá-la, o quanto lembram daquilo, seu grau de propensão a erros e o quanto gostam de utilizá-la. Se as pessoas não puderem ou não utilizarem um recurso, ele pode muito bem não existir.[4]
\end{abstract}

Na web a usabilidade é um fator de grande relevância, especialmente quando o objetivo é atingir um público bastante abrangente como, no caso, a CV-Muzar. A mensuração da usabilidade é importante, pois é a partir desses resultados que se pode identificar a facilidade que usuários têm ou não em utilizar determinada ferramenta e atingir o objetivo a que se propõe. A Figura 3 apresenta um fluxograma, destacando os objetivos principais de uma ferramenta virtual, assim como as funções fundamentais que deve conter.

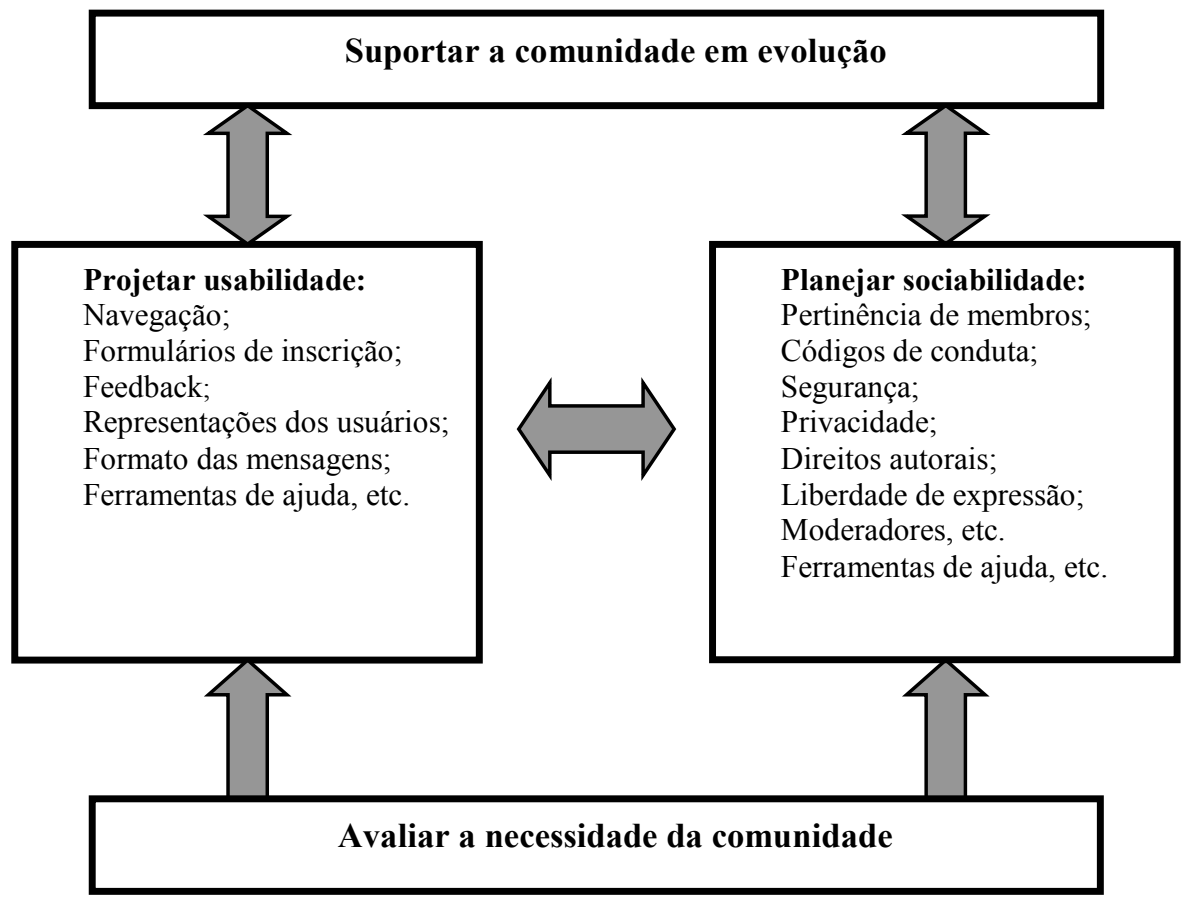

Figura 3: Elementos da usabilidade de uma ferramenta virtual [5]

Dessa forma, analisando o fluxograma, esses objetivos podem ser divididos em dois grupos principais: um referente às ferramentas de uso direto do usuário (interface) e que devem ter sua usabilidade avaliada, como aspectos relacionados à navegação, ferramentas de interação, formatos de mensagens, formulários, entre outros; outro que se relaciona indiretamente com os usuários, como segurança dos dados digitados, direitos autorais dos arquivos enviados, privacidade e códigos de conduta.

Compreender o funcionamento desses dois grupos dentro da CV-Muzar é de suma importância, tendo em vista que, por ser um ambiente voltado a um grupo de pessoas cuja principal semelhança entre si é a busca pelo aprendizado, sendo diferentes as características, como faixa etária, experiência com a ferramenta, escolaridade e nível de conhecimentos. Para tanto, deverá haver a presença de um moderador (desenvolvedores) que verifique 
as postagens, os dados e arquivos publicados, visando desenvolver um espaço saudável de aprendizagem informal.

\subsection{ISO 9241-11}

A ISO 9241-11 é a $11^{\text {a }}$ parte da ABNT (Associação Brasileira de Normas Técnicas) e trata de orientações sobre usabilidade, esclarecendo os benefícios de medir usabilidade em termos de desempenho e satisfação do usuário, definindo usabilidade e explicando como identificar a informação necessária a ser considerada na especificação ou avaliação. Orienta como descrever explicitamente o contexto de uso do produto e as medidas relevantes de usabilidade, por meio de princípios e técnicas gerais, ao invés de requisitos para usar métodos específicos.

Entre os benefícios do embasamento na ISO 9241-11 para mensuração da usabilidade, destacam-se a sua utilização para identificar os aspectos de usabilidade e os componentes do contexto de uso a serem considerados no momento da especificação, projeto ou avaliação de usabilidade de um produto. E ainda o uso do nível da satisfação dos usuários para medir o grau em que um produto é usável num contexto particular. [3]

\subsubsection{Metodologia proposta pela ISO 9241-11}

A metodologia para nivelar a usabilidade de determinada ferramenta a partir dessa norma leva em consideração a seguinte estrutura: proposta; descrição dos objetivos; contexto de uso; medidas de usabilidade (eficácia, eficiência e satisfação); interpretação das medidas, os quais devem ser especificados previamente e durante o desenvolvimento do produto (hardware, software ou serviços). Em síntese, essa estrutura compreende os seguintes passos:

- proposta: descreve os componentes e a relação pretendida entre eles;

- componentes de usabilidade: é necessário identificar os objetivos e decompor eficácia, eficiência e satisfação e os componentes do contexto de uso em subcomponentes com atributos mensuráveis e verificáveis;

- informações: apontamento dos objetivos e o contexto de uso da ferramenta (descrição dos usuários, tarefas, equipamentos e ambientes), mensuração desejada de eficácia, eficiência e satisfação;

- descrição dos objetivos: os objetivos de uso de um produto devem ser descritos. Essa etapa é fundamental para orientar quais componentes serão necessários para que se atinjam os objetivos propostos. Os objetivos podem ser decompostos em subobjetivos, os quais especificam componentes de um objetivo global e os critérios que irão satisfazer aquele objetivo;

- contexto de uso: inclui a descrição dos usuários (como as características relevantes: conhecimento, habilidade, níveis de experiência, educação, treinamento, atributos físicos e capacidades sensoriais e motoras, entre outros), das tarefas (atividades executadas para alcançar um objetivo), equipamentos (descrição do hardware, software e dos materiais associados com o computador podem ser um conjunto de produtos, um ou mais dos quais podem ser o foco da especificação ou avaliação de usabilidade), ambientes (características relevantes do ambiente físico e social);

- medidas de usabilidade: eficácia (relacionada aos objetivos ou subobjetivos do usuário quanto à acurácia e à completude com que esses objetivos podem ser alcançados), eficiência (relacionam o nível de eficácia alcançada ao dispêndio de recursos, os quais podem incluir esforço mental ou físico, tempo, custos materiais ou financeiros), satisfação (mede a extensão pela qual os usuários estão livres de desconforto e suas atitudes em relação ao uso do produto);

- interpretação das medidas: atentando na generalização dos resultados de qualquer medição de usabilidade para outro contexto qualquer que pode ter diferenças significativas de tipos de usuários, tarefas ou ambientes.

Desse modo, a ISO 9241 mostra-se como um instrumento de avaliação viável para medir a usabilidade, levando em consideração algumas heurísticas e partindo de um objetivo para identificar a eficácia, eficiência e satisfação do produto, assim como os componentes do contexto de uso em subcomponentes com atributos que possam ser mensuráveis e verificáveis.[3] 
A ISO 9241 é uma lista de verificação testada, utilizada por profissionais para a inspeção de interfaces.

\subsection{ErgoList}

Existem outros projetos que se destinam a apoiar exercícios de inspeção de interfaces de maneira a descobrir falhas ergonômicas em interfaces. Dentre esses projetos está o ErgoList [6], que dispõe de 18 checklists responsáveis por avaliar: concisão; mensagens de erro; flexibilidade; legibilidade; significados; proteção contra erros; agrupamento de formatos; experiência do usuário; presteza; controle do usuário; correção de erros; consistência; agrupamento por localização; densidade de erro; feedback; compatibilidade; ações explicitas e ações mínimas. O Ergolist é uma lista de verificação de exigências ergonômicas para interfaces com o usuário.

O uso do Ergolist para avaliar a usabilidade da interface da CV-Muzar vem a facilitar o desenvolvimento da metodologia proposta pelo ISO 9241-11, uma vez que essa norma propõe a adoção de medidas reais de usabilidade.

A avaliação da usabilidade da CV-Muzar foi realizada utilizando os dois métodos mencionados. Na próxima seção serão apresentados os resultados obtidos.

\section{Inspeção de usabilidade na CV-Muzar}

Seguindo as normas propostas pela ISO 9241-11, a interface da CV-Muzar foi avaliada a fim de propor uma nova interface que atendesse aos requisitos básicos da usabilidade. Além desse instrumento, utilizou-se também o checklist Ergolist, que compreende 194 questões, divididas em 18 critérios (Figura 4), que "constituem um conjunto de qualidades ergonômicas que as interfaces humano-computador deveriam apresentar" [7], gerando, ao término do questionário, um relatório com todas as respostas obtidas da inspeção da interface.

As respostas dadas às questões são selecionadas de acordo com a conformidade, podendo estar "conforme", "não conforme" e "não aplicável” à interface. A seguir tem-se a página inicial do Ergolist.

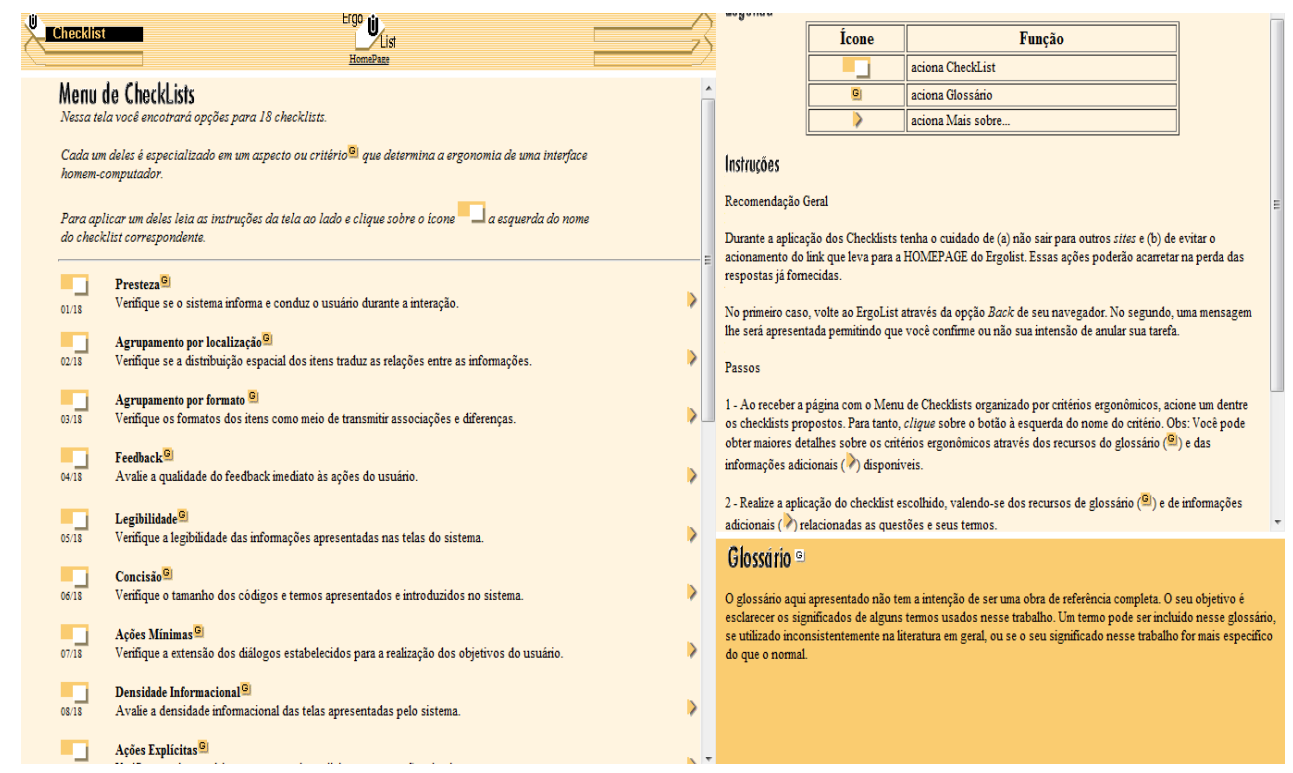

Figura 4: Página inicial do checklist do Ergolist [8]

Para a inspeção da CV-Muzar, todas as 194 foram respondidas, estando 85 delas conformes, 40 não conformes e 69 não aplicáveis à interface, conforme apresentado na Figura 5. 


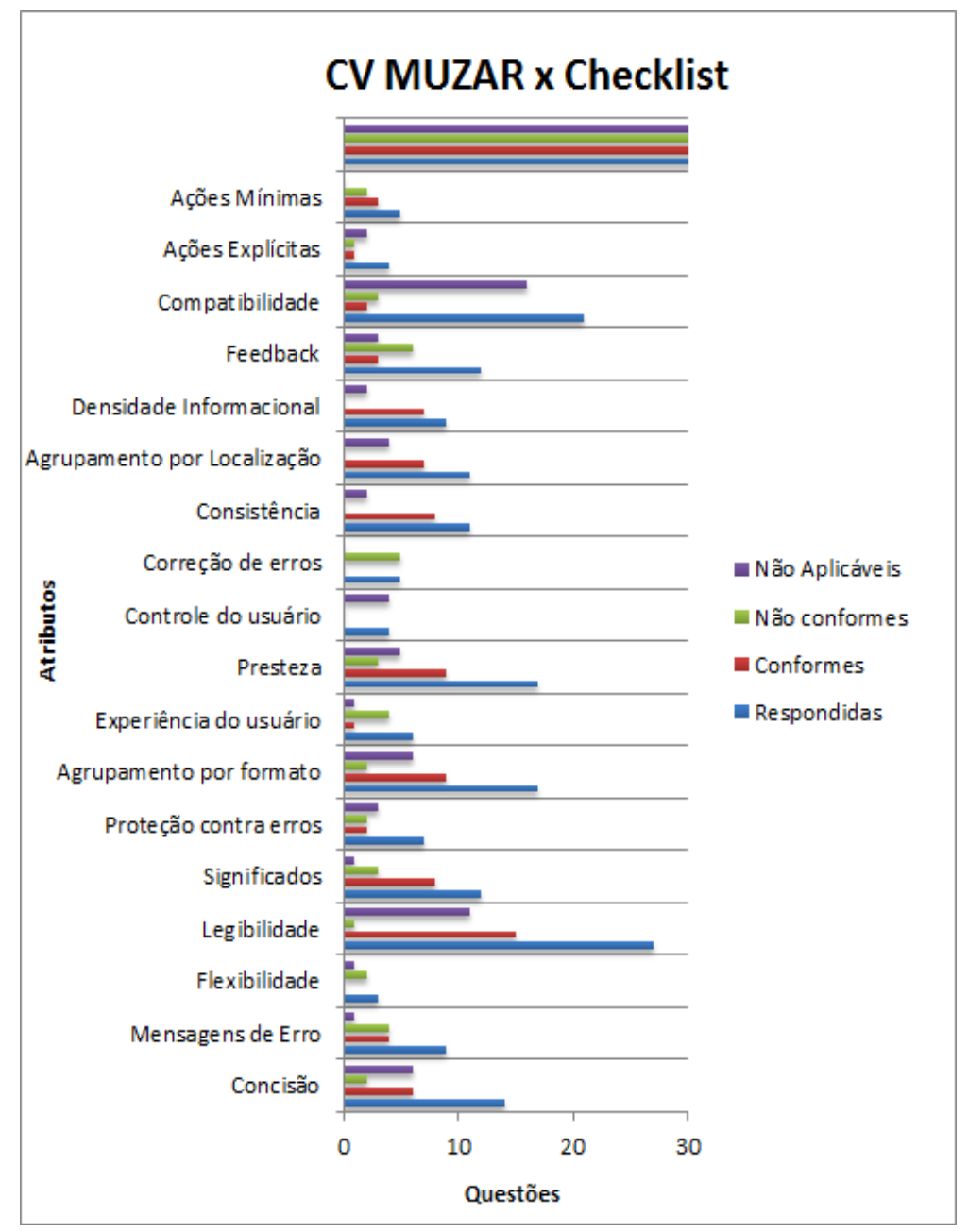

Figura 5: Resultados do checklist do ErgoList

Com o auxílio do checklist na avaliação da interface da CV-Muzar, pode-se identificar quais os pontos que atingem um nível de usabilidade satisfatório ou que não contribuem para a eficiência e eficácia da ferramenta.

Dos atributos avaliados no Ergolist, destacam-se os aspectos não conformes, como ilustra a Figura 5. Desses, os que apresentam maior número de questões nesse sentido estão listados na sequência, assim como as falhas que foram evidenciadas com a avaliação:

- concisão: percebeu-se a ausência desse atributo especialmente na página principal da CV-Muzar, onde os ícones não são econômicos do ponto de vista do espaço;

- mensagens de erro: as mensagens de erro geradas não auxiliam o usuário na solução do erro encontrado e, além disso, o usuário não tem a opção de escolher o nível de detalhe das mensagens de erro em função de seu nível de conhecimento. Outro ponto a ser analisado é o fato de as mensagens de erro não terem seu conteúdo modificado quando na repetição imediata do mesmo erro pelo mesmo usuário;

- legibilidade: há o uso de abreviaturas que não trazem clareza ao usuário, como em usuários M-Lom, ou OA. Essas siglas podem ser desconhecidas para alguns usuários, especialmente para os que não têm experiência no uso da ferramenta; 
- $\quad$ proteção contra erros: ao final de uma sessão de trabalho, o sistema não informa sobre o risco de perda dos dados, ou seja, após o preenchimento de um formulário, ao sair da página, o usuário não é informado sobre a possibilidade de seus dados não terem sido salvos;

- $\quad$ experiência do usuário: o sistema não é adaptado para diferentes públicos;

- $\quad$ correção de erros: depois de um erro de digitação de um comando ou de dados, o usuário não tem a possibilidade de corrigir somente a parte dos dados incorretos. Por exemplo, após criar uma nova subcomunidade não há opção para que esse item seja editado novamente;

- feedback: há ausência de feedbacks informando e orientando as ações do usuário.

Como descrito na figura, elaborada a partir dos dados obtidos no laudo final gerado pelo Ergolist, a interface atual da CV-Muzar possui alguns pontos que pecam quanto à usabilidade. A presente ferramenta voltase a um público de faixas etárias heterogêneas e de níveis de experiência com o uso de ferramentas virtuais distintos.

Desse modo, há a necessidade de adaptar essa interface para que atenda aos principais critérios de avaliação da usabilidade e, assim, satisfazendo o objetivo para o qual essa foi criada. Percebeu-se, após a inspeção com o Ergolista, a ausência das seguintes funções e componentes, as quais deverão ser inseridas para que se atinja um nível de usabilidade aceitável:

- refinar as mensagens de erros, identificando qual é o erro que o usuário está cometendo (senhas inválidas, por exemplo) e indicar uma solução válida;

- considerar a experiência prévia do usuário, disponibilizando funções distintas a cada grupo, de acordo com a experiência do usuário com a ferramenta, adicionando ou retirando determinadas funcionalidades, de acordo com o usuário;

- disponibilizar a criação de fóruns mais específicos, que permitam aos usuários uma discussão sobre determinado assunto do seu interesse;

- possibilitar a edição do perfil dos usuários, permitindo a alteração de dados pessoais, como idade e outras informações que estejam relacionados com a comunidade;

- padronizar as listas de menus;

- rever a necessidade dos tópicos, como interações-gráficos, removendo e/ou alterando quando se mostrarem desnecessários;

- verificar os endereços dos links e o compartilhamento de arquivos, corrigindo o endereço ao qual tal link redireciona;

- validar todos os formulários/mensagens;

- disponibilizar um FAQ-perguntas frequentes, auxiliando o usuário na solução de problemas e dúvidas que venham a surgir;

- enviar convites aos participantes-inativos/novos participantes.

Diante desse contexto, é possível verificar a necessidade de alteração de algumas funcionalidades e a implementação de novas, como também a exclusão de outras para que a interface da CV-Muzar se mostre apta a servir de maneira eficaz como uma ferramenta de interação e conexão entre o público do museu.

Foi proposta, dessa forma, uma nova interface para a CV-Muzar, pensando-se nos resultados dos testes de usabilidade. A nova interface, ilustrada na Figura 6, está em fase de implementação. 


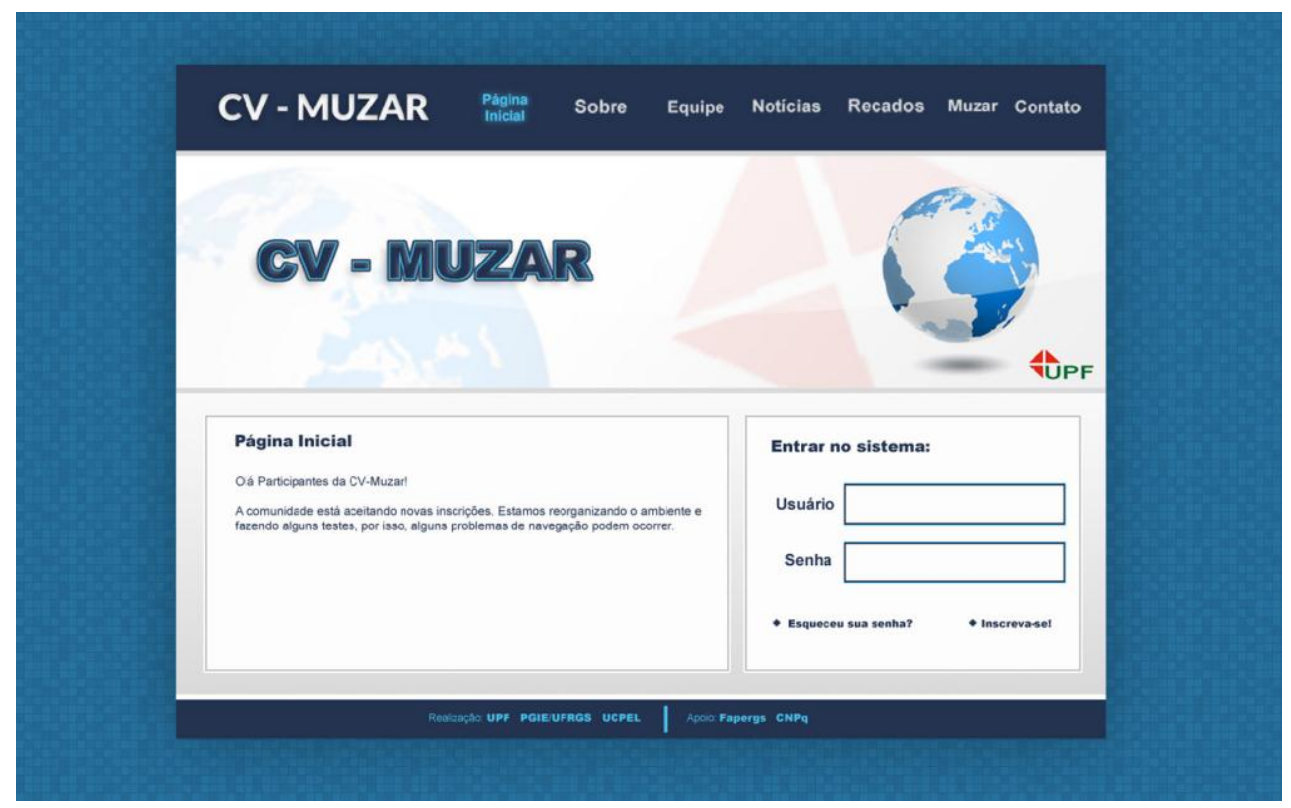

Figura 6: Nova interface da CV-Muzar.

\section{Considerações finais}

Avaliar a usabilidade da interface da CV-Muzar, tendo como base a ISO 9241-11 e o checklist do Ergolist para fazer a mensuração, foi uma forma válida de identificar problemas que possam dificultar a interação entre os usuários. Como foi dito anteriormente, uma interface atrativa e de fácil compreensão é fundamental para que aqueles que a utilizarão se sintam atraídos a interagir, auxiliando, com isso, na aprendizagem informal.

A partir desses resultados, foi possível pensar em uma interface nova, que corresponda às exigências apresentadas pelas ferramentas de mensuração de usabilidade, seguindo as recomendações da ISO 9241-11, de modo a servir como um ambiente de aprendizagem informal utilizado por qualquer perfil de usuário que venha a interagir.

Incorporar as novas funcionalidades propostas visando à usabilidade é um objetivo buscado pelos desenvolvedores desse projeto, porém a CV-Muzar não deve se tornar restrita a essas alterações. Novas alterações poderão ser exigidas a partir da experiência do usuário, sendo esta a melhor medida de eficiência. $\mathrm{O}$ sucesso de uma comunidade virtual deve levar em consideração a evolução dessa ferramenta, possibilitando a implementação de novas funções sempre que necessário.

\section{Referências}

[1] DE MARCHI, A. C. B; TESTA, C. D; COSTA, A. C. R. Um ambiente de comunidade virtual baseado em objetos de aprendizagem para apoiar a aprendizagem em museus, 2005 . Disponível em: <http://seer.ufrgs.br/renote/article/view/13794/7982>. Acesso em: 30 mai. 2011.

[2] DE MARCHI, A. C. B. Um ambiente de suporte a comunidades virtuais baseadas em repositórios de objetos de aprendizagem para apoio à aprendizagem informal em museus. 2006. Tese (Doutorado), UFRGS, Porto Alegre. 225p.

[3] ABNT. ISO 9241-11: Requisitos ergonômicos para trabalho de escritórios com computadores. Parte 11 Orientações sobre usabilidade, 2002. Disponível em: <http://www.inf.ufsc.br/ cybis/pg2003/iso9241-11F2.pdf> Acesso em: 5 jun. 2011. 
[4] NIELSEN, J.; LORANGER, H.; LESSA, L. Usabilidade na web. Rio de Janeiro: Elsevier, 2007.

[5] USABILIZA. Consultoria em usabilidade de software. Disponível em: $<$ http://www.usabiliza.com/noticias/2010/4/5/projetando-comunidades-virtuais-usabilidade-esociabilidade.html >. Acesso em: 17 jun. 2011.

[6] CYBIS, W. ErgoList. 2011. Disponível em: 〈http://www.labiutil.inf.ufsc.br/ergolist>. Acesso em: 20 jun. 2011.

[7] LABIUTIL - LABORATÓRIO DE UTILIZABILIDADE. Critérios ergonômicos para avaliação de interfaces homem-computador. Disponível em: <http://www.labiutil.inf.ufsc.br/CriteriosErgonomicos/Abertura.html>. Acesso em: 20 jun. 2011.

[8] CHECKLIST. Menu de checklists. Disponível em: 〈http://www.labiutil.inf.ufsc.br/ergolist/check.htm〉. Acesso em: 20 jun. 2011. 